MATEC Web of Conferences 33, 03010 (2015)

DOI: $10.1051 /$ matecconf/ 20153303010

(C) Owned by the authors, published by EDP Sciences, 2015

\title{
Functional textiles driven by transforming NiTi wires
}

\author{
Luděk Heller ${ }^{1, a}$, K. Janouchová ${ }^{1}$, P. Šittner ${ }^{1}$ and D. Vokoun ${ }^{1}$ \\ ${ }^{1}$ Institute of Physics AS CR, v. v. i., Department of Functional Materials, Na Slovance 2, 18221 Prague, Czech Republic
}

\begin{abstract}
Over last ten years, we have carried out extensive research on the use of thin NiTi wires for advanced functional textiles. In this work we discuss general challenges and opportunities in the design, production and processing of NiTi textiles stemming from the fact that NiTi is martensitically transforming metal. As a case example, application of weft knitting technology to NiTi wires is discussed in detail covering technological aspects related to textile processing, shape setting as well as multiaxial thermomechanical properties of final products. Finally, two weft knitted NiTi textile proof-of-concepts with a promising application potential are presented. First, a textile based actuator with large strokes and low forces characteristics is introduced. Second, 3D textiles with temperature-adaptive cross-section height for applications in technical or protective textiles are described.
\end{abstract}

\section{Introduction}

We have carried out extensive research on thin NiTi wires with diameters of tens to hundreds microns over past ten years [1-3] motivated by their potential use for advanced functional textiles [4-5]. Although being just moderately textile-compatible, the potential of the use of thin NiTi wires in textiles stems from their unique functional and structural properties [1] that may give rise to high added value functional textiles [5]. Regarding the textile compatibility, thin NiTi wires show outstanding functional properties out of which the superelasticity providing up to $10 \%$ of reversible deformation [1] makes these wires fairly deformation-compatible with common textile fibres. Similarly, the superelasticity combined with the low diameter of NiTi filaments allows for large reversible deflections commonly experienced by fibres in textiles subjected to mechanical loads. The use of thin NiTi wires in textiles is further seen beneficial for functional properties such as temperature driven reversible changes of Young's modulus through martensitic transformations [6] (switching between stiffer hot austenite phase $\sim 75 \mathrm{GPa}$ and softer cold R-phase or martensite phases $\sim 40 \mathrm{GPa}$ ), pseudoplastic behaviour of cold martensite phase [7] (recoverable deformation up-to $10 \%$ due to martensite detwinning), and thermally induced shape memory effect [7] (recovery of detwinned martensite upon heating) may provide textiles with advanced functional properties. Finally, cold drawn thin NiTi wires can be shape set [8] in complex curved shapes through annealing termed shape setting, which may be advantageously used as an additional textile processing step. To sum up, NiTi textiles may provide advanced functional properties stemming from the combined effect

\footnotetext{
$\overline{{ }^{a} \text { Corresponding author: heller@fzu.cz }}$
}

of textile patterns and textile-compatible outstanding functional properties of thin NiTi wires.

\section{Challenges and opportunities in design of NiTi textiles}

Textile processing of thin NiTi textiles brings about several issues that must be considered in the design of NiTi textiles.

\subsection{Shape setting}

While interlacing thin NiTi wires during textile processing (see knitting processing in Fig. 1a), deformation energy is stored in NiTi wires due to interlacing in textile patterns (see Fig. 1a). As the deformation is mostly due to combined torsion-bending, the amount of the deformation energy depends on the textile pattern and the wire diameter. In general, this stored energy is much higher compared to common textiles as the stiffness and yield stress for plasticity of thin NiTi wires are generally higher than that of other textile fibres (Young's modulus of a cold drawn NiTi wire is about $70 \mathrm{GPa}$, yield stress for plasticity is about $1.7 \mathrm{GPa}$ ). As a result, the NiTi textile is highly distorted when removed from the textile machine. For example, Fig. 1b shows wrapping of a plain weft knitted NiTi textile made from as drawn $0.2 \mathrm{~mm}$ thin NiTi filament after being removed from the knitting machine. In order to restore the plain shape, the textile is shape set i.e. it is flattened, constrained, and exposed to temperatures usually ranging from $300^{\circ} \mathrm{C}$ to $500^{\circ} \mathrm{C}$ for $10-30$ minutes [8]. Fig. 1c shows a plain-shape set weft knitted NiTi textile. The shape setting is the major obstacle for designing hybrid NiTi textiles combining thin NiTi wires

This is an Open Access article distributed under the terms of the Creative Commons Attribution License 4.0, which permits unrestricted use distribution, and reproduction in any medium, provided the original work is properly cited. 
with additional textile fibres that usually don't resist to such high temperatures. Therefore, non-standard heat resistant textile fibres such as basalt or Aramid yarns must be considered or textile fibres must be incorporated after the shape setting. However, the shape setting can be seen also as an opportunity, since it allows for defining the pattern and macroscopic shape of NiTi textiles. For common textiles, this is imprinted by textile processing only. For example, 3D NiTi textiles may be created from simple plain textiles (see 3D-shape set weft knitted textile in Fig. 1c). Morphology of the textile patterns, which is again for common textiles defined only by the textile processing, can be adjusted through the shape setting.

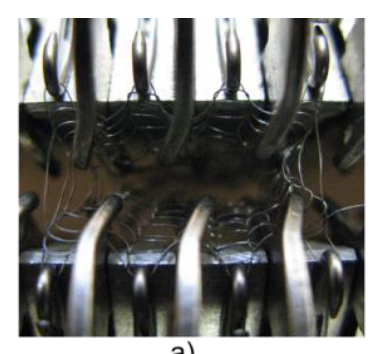

a)

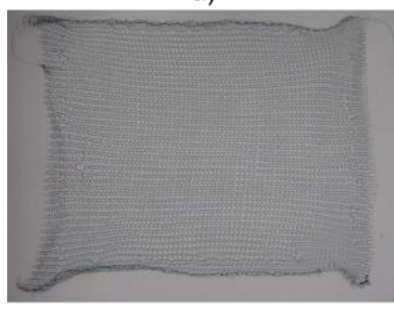

c)

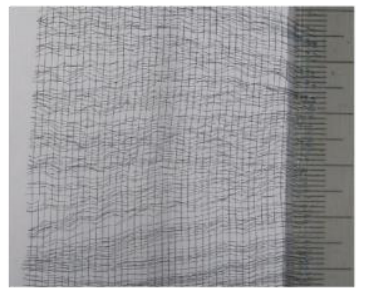

e)

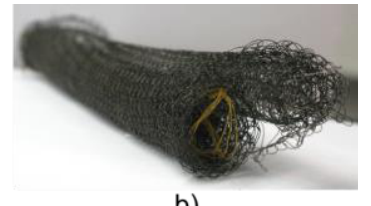

b)

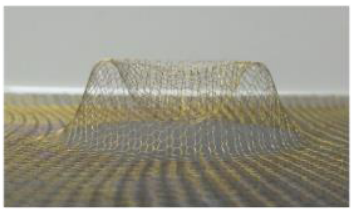

d)

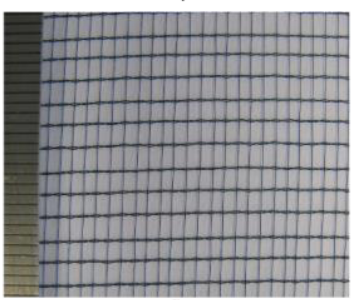

f)

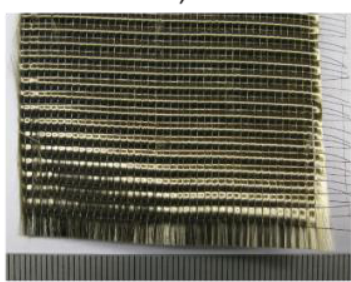

g)
Figure 1. a) Detailed view of $0.1 \mathrm{~mm}$ NiTi in the process of the circular weft knitting. Note that the wire distortion is partly accommodated by elastic deformation; b) Weft knitted NiTi textile after removal from the knitting machine - wrapping due to stored elastic deformation energy; c) Weft knitted NiTi textile after plain-shape setting i.e. the initially wrapped textile is flattened, constrained, and exposed to $450^{\circ} \mathrm{C}$ for $30 \mathrm{~min}$; d) Weft knitted NiTi textile after $3 \mathrm{D}$-shape setting i.e. the initially wrapped textile is placed into a mould and exposed to $450^{\circ} \mathrm{C}$ for $30 \mathrm{~min}$; e) NiTi woven textile with irregular pattern due to wire sliding; f) Woven NiTi textiles with leno woven pattern ensuring its regularity; g) Hybrid NiTi textile with basal fibres altering NiTi wires to ensure the pattern regularity.

\subsection{Material consumption}

One of the key issues in NiTi textiles development is the waste of material as NiTi filaments are costly compared to standard textile fibres. Large quantity of NiTi is wasted in some textile processing methods, such as weaving and warp knitting, for setting up the warp - i.e. the parallel set of wires. In addition, setting up the warp is a highly time consuming operation.

\subsection{Machinery wear}

The textile machinery wear might be considered as a potential technical and economic risk as we deal with stiff and hard metallic wires that are being highly distorted during textile processing (see Fig. 1a). However, no excessive wearing was identified during our sampling activities though it certainly must be considered for higher production rates.

\subsection{NiTi wire friction}

The low friction of thin NiTi wires combined with elastic deformation relieve by shape setting makes woven patterns loose and prone to becoming irregular upon handling them, as seen in Fig. 1e. Such instability may be dealt with by using a special weaving pattern called leno weave, where two warp yarns are twisted around the weft yarns (see Fig. 1f). A second option is to create weaving patterns from thin NiTi wires alternated with textile fibres ensuring the pattern tightening. See Fig. $1 \mathrm{~g}$ as an example, where heat resistant basalt fibres are combined with thin NiTi wires.

\section{Mechanical behaviour of NiTi textiles}

We applied three standard textile processing technologies, namely, weaving, weft knitting and warp knitting, in order to investigate mechanical responses of NiTi textiles with respect to the textile morphology. Fig. 2 shows uniaxial tensile responses of $\mathrm{NiTi}$ textile manufactured from an as drawn $0.1 \mathrm{~mm} \mathrm{NiTi}$ wire with nominal composition of 50.9 at. $\% \mathrm{Ni}$ using these technologies. The wire is specified by manufacturer as a medical graded wire being superelastic after shape setting is applied i.e. Austenite finish temperature (Af) is below the room temperature. Clearly, the weaving pattern forming an orthogonal mesh of NiTi wires loaded along the principal directions, shows a response similar to standard superelastic tensile curve of the straight wire (see blue curve in Fig. 2), whereas knitted patterns show completely different responses along principal directions (see red and green curves in Fig. 2) since bending of individual knitting loops (knits) is the dominating deformation mechanism.

Further on we decided to analyse in detail the properties of weft knitted textiles mainly for two reasons. First, the behaviour of woven NiTi textiles is rather straightforward with respect to the behaviour of a single NiTi wire. Second, weaving as well as warp knitting, requires a large quantity of NiTi wires, part of which is wasted as pointed out earlier. Contrarily, weft knitting is by far the least time-consuming of the three technologies and, in addition, the weft knitted patterns feature interesting properties such as high stretchability and an easy-to-tune 
mechanical response by changing the knit shape and/or size.

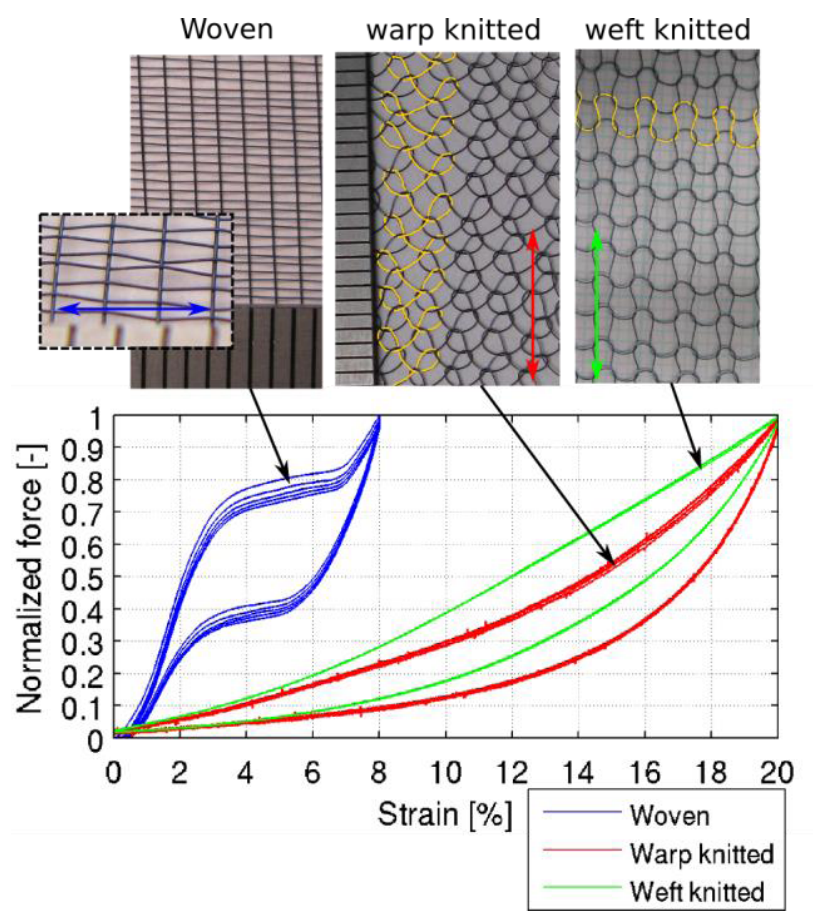

Figure 2. Uniaxial cyclic tensile responses of woven, weft and warp knitted NiTi textiles manufactured from as drawn $0.1 \mathrm{NiTi}$ wires with nominal composition of 50.9 at.\% Ni. NiTi textiles were plain-shape set at $450^{\circ} \mathrm{C}$ for $30 \mathrm{~min}$.

\section{Thermomechanical behaviour of weft knitted NiTi textiles}

As pointed out above, knitting patterns feature interesting structural behaviour, which might be advantageously combined with shape setting and functional properties of Niti wires to create functional textiles. Indeed, so called active knits have been reported as a possible solution for actuators capable of simultaneous large forces and strains in form of complex 3D distributed motions required for aeronautics [9]. However, the reported approach relies on smart knit architecture disregarding all the unique opportunities arising from shape setting.

\subsection{Shape setting}

Shape setting can provide further options for tuning thermomechanical properties. For examples, the mechanical constraints applied during shape setting effectively change the knit pattern as seen in Fig. 3 showing three different knit patterns made out of the identical textiles manufactured using the same textile processing but shape set under different constraints. As a result, the textiles exhibit different mechanical responses and their anisotropy as illustrated in Fig. 3 showing tensile responses along two principal directions of two textiles having different knits' shapes shown in Fig. 3a (blue tensile curves) and $3 \mathrm{~b}$ (red tensile curves). The anisotropy of tensile responses is evaluated in a simplified manner by relative changes in tensile forces at
$10 \%$ of deformation measured along the course-wise (solid line curves in graph Fig. 3d) and wale-wise (dashed line curves in Fig. 3d) principal directions. Clearly, applying appropriate constraints during shape setting, the textile may either exhibit relatively comparable responses and secant moduli along the two principal directions or be highly compliant along one principal direction with respect to the other one. Therefore, the shape setting can be effectively used to tune the mechanical response of weft knitted NiTi textiles.

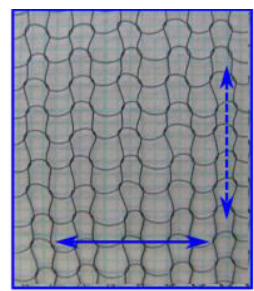

a)

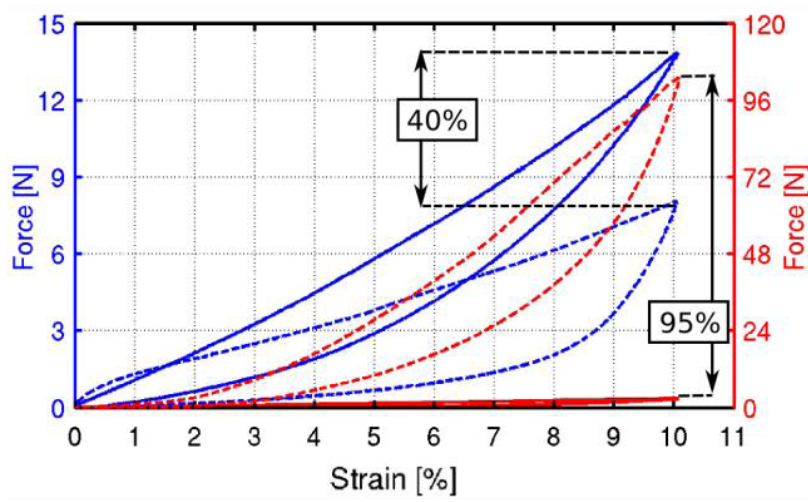

d)
Figure 3. a),b),c) Photographs showing the weft knitted patterns made from identically textile processed samples through applying particular deformation constraints during shape setting. Graph in d) show tensile responses of textiles with patterns shown in in-sets a) and b) made from $0.1 \mathrm{~mm} \mathrm{NiTi}$ wires that are superelastic at room temperature i.e. $A_{f}<$ room temperature.

\subsection{Local superelastic deformation mode}

Generally, macroscopic mechanical response of textiles is determined to large extent by local deformation of textile patterns. In order to qualitatively evaluate the local deformation mode of weft knitted NiTi textiles, we recorded knit deformation during a well defined biaxial loading. This was carried out using a bulge test commonly used for testing membranes. In this case the weft knitted NiTi textile supported by a polymer membrane of negligible stiffness was placed and clamped over an aperture of $100 \mathrm{~mm}$; then the increasing inner air overpressure bulged the textile forming a hemisphere when pressurized. Although the entire bulged textile is subjected to inhomogeneous biaxial loadings, equibiaxial loading is applied right in the centre of the bulged textile. Fig. 4 shows typical bulge response in terms of applied overpressure and measured height of the formed hemisphere (denoted as Stroke of the pole) for a plain- 
shaped set superelastic NiTi textiles made from $0.1 \mathrm{~mm}$ NiTi wire. In-set photographs show knits in the centre of the bulged textile at different stages of bulging. Clearly, deformation of the knits is realized through straightening of curved segments and hence bending is expected to prevail as a wire loading mode.

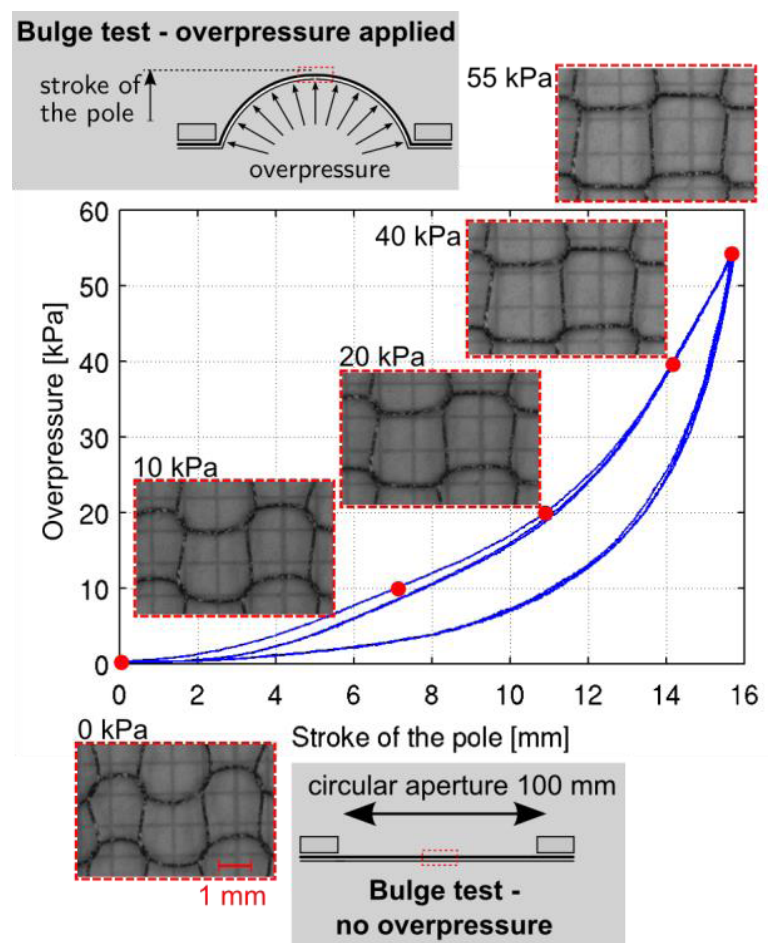

Figure 4. Mechanical response of a superelastic weft knitted NiTi textile made from $0.1 \mathrm{~mm}$ wire. The textile was underlaid with a compliant polymer membrane and subjected to bulging by air overpressure. In-set photographs show the deformation of knits at centre of bulged area of diameter $100 \mathrm{~mm}$ where equibiaxial loading is applied.

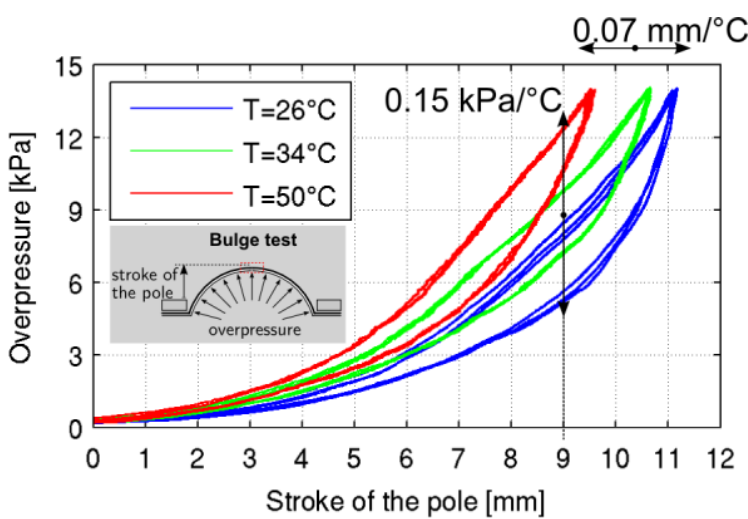

Figure 5. Mechanical responses of a superelastic weft knitted NiTi textile made from 0.1 NiTi wire. The textile was underlaid with a compliant polymer membrane and subjected to bulging by air overpressure at three different temperatures. The temperature sensitivity was evaluated as temperature induced pressure change of $0.15 \mathrm{kPa} /{ }^{\circ} \mathrm{C}$ at $9 \mathrm{~mm}$ of the stroke of the pole and as temperature induced stroke of the pole change of 0.07 $\mathrm{mm} /{ }^{\circ} \mathrm{C}$ at pressure of $14 \mathrm{kPa}$.

In order to analyse the involvement of martensitic transformation /MT/ in the overall deformation of knits, tests at different temperatures were performed. No temperature sensitivity of bulge responses is expected for purely elastic deformation mode. As seen in Fig. 5, the response of weft knitted NiTi textiles to bulging is sensitive to temperature and, therefore, we believe the local deformation of knits is at least partly accommodated through MT. Quantitatively, as indicated in Fig. 5, temperature induced pressure change of $0.15 \mathrm{kPa} /{ }^{\circ} \mathrm{C}$ was measured at $9 \mathrm{~mm}$ of the stroke of the pole and the stroke of the pole change of $0.07 \mathrm{~mm} /{ }^{\circ} \mathrm{C}$ was measured at 14 $\mathrm{kPa}$.

\subsection{Local pseudoplastic deformation mode}

NiTi wires can deform pseudoplastically by detwinning of martensite variants [7]. We tested the effect of pseudoplastic deformation on mechanical response of weft knitted NiTi textiles made from $0.1 \mathrm{~mm} \mathrm{NiTi}$ wires with nominal composition 49.8 at.\% Ni. After shape setting, martensitic phase is present in this wire at room temperature as checked by differential scanning calorimetry (DSC) measurement that is not shown here for the sake of brevity. The response of this textile to cyclic uniaxial loading along the wale-wise principal direction (see black arrows in the inset photograph in Fig. 6) is presented in Fig. 6. In addition, in-set photographs of knits in initial shape and after the first cycle is displayed to clearly show that the knit deflection is not recovered after unloading. However, upon heating above $A_{f}$ temperature, the initial knit pattern is recovered which is again not shown here for the sake of brevity. Therefore, we believe the pseudoplastic deformation by martensite detwinning presumably causes the nonrecovered deformation.

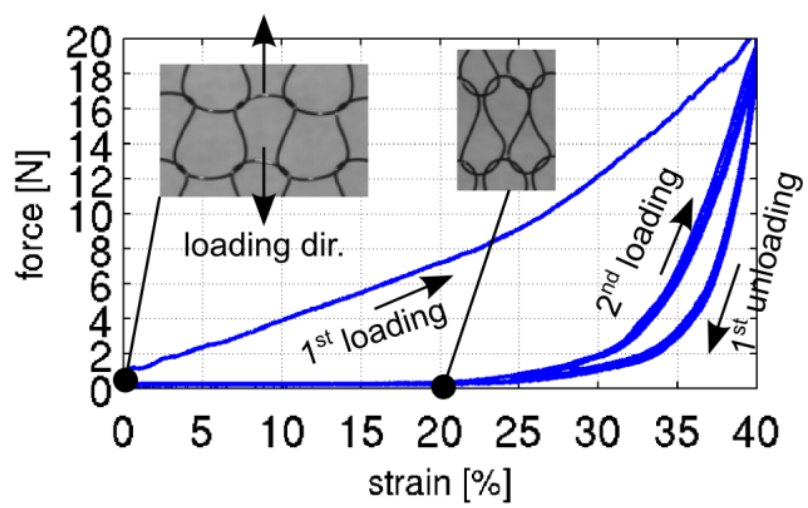

Figure 6. Uniaxial along the wale-wise pricipal direction tensile response of a pseudoplastic weft knitted NiTi textile made from $0.1 \mathrm{NiTi}$ wire. In-set photographs show the initial knit shape and the non-recovered knit shape after $1^{\text {st }}$ unloading.

\section{$5 \mathrm{NiTi}$ textiles with application potential}

In this section we provide two examples of NiTi textiles with application potential. The design of these textiles relies on three factors: i) temperature induced change of Young's modulus of NiTi wires; ii) deflection dominated local deformation of weft knitted textiles; iii) smart weft knitted patterns. 


\subsection{R-phase NiTi textile actuator}

We designed a "high strokes-low forces" actuator taking advantage of R-phase transformation and a circular-weft knitted pattern. Premartensitic R-phase transformation is known to exhibit favourably low hysteresis but disadvantageously low transformation strain $(\sim 0.5 \%)$ compared to MT. However, weft-knitted wire architecture provides strain-multiplying affect through structural deflections. Circular weft knitting was used instead of plain weft knitting that is prone to damage followed by unravelling at free-edges being excessively loaded upon stretching. Circular weft knitting allows to create a more robust tubular structure as seen in in-set rectangle in Fig. 8.

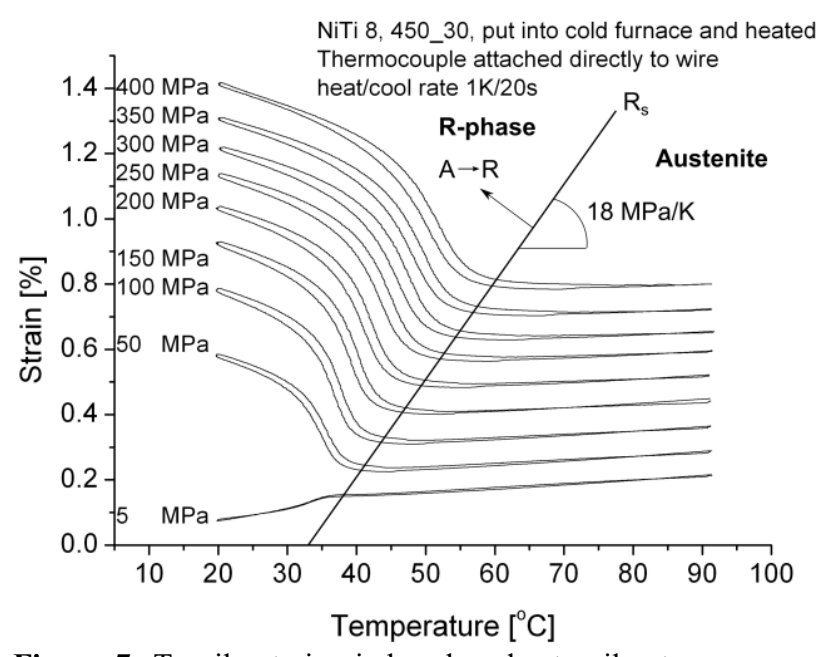

Figure 7. Tensile strains induced under tensile stresses upon temperature cycling of $0.1 \mathrm{~mm} \mathrm{NiTi}$ wire with nominal composition of 50.59 at.\% Ni., cold drawn and shape set in straight shape at $450^{\circ} \mathrm{C}$ for $30 \mathrm{~min}$. The strains are due to reversible Austenite to R-phase transformation

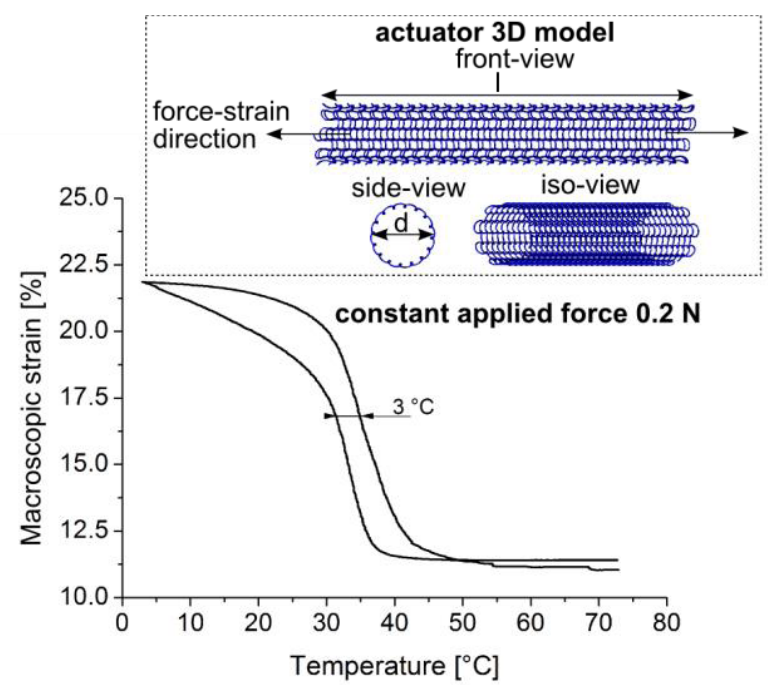

Figure 8. Macroscopic strains induced by heating and cooling of NiTi textile based actuator subjected to constant force of 0.2 $\mathrm{N}$. The geometry of the actuator characterized by diameter $d$ and length $l$ is presented in in-set rectangle.

We used a cold drawn NiTi wire of diameter $0.1 \mathrm{~mm}$ with nominal composition of 50.59 at.\% $\mathrm{Ni}$ that was circular weft knitted and then shape set to form a tubular structure with diameter $d$ of $10 \mathrm{~mm}$ and length $l$ of $\sim 100 \mathrm{~mm}$ (see in-set rectangle in Fig. 8 for geometrical parameters definition). The shape set NiTi wire presents R-phase at room temperature while austenite finish temperature is at $40^{\circ} \mathrm{C}$ and martensite start temperature is at $-80^{\circ} \mathrm{C}$ as measured by DSC data of which is not shown here for the sake of brevity. The large separation of the R-phase from the martensitic phase allows to use austenite-R-phase transition for high stresses actuation as seen in Fig. 7 showing actuation tensile strains during thermal cycling at constant applied tensile stresses.

Combined effect of textile architecture and NiTi wire with isolated Austenite-R-phase transition allows to design "high strokes-low forces" actuator with low hysteresis as seen in Fig. 8 showing reversible macroscopic strain reaching $10 \%$ upon temperature cycling against constant load of $0.2 \mathrm{~N}$.

\subsection{Temperature responsive 3D NiTi textiles with adaptive cross-section}

We designed a lightweight hollow 3D NiTi textile that features a hollow cross-section deforming in response to applied external loads and changing temperature. The 3D NiTi textile is based on a unique weft knitted pattern consisting of two layers that are periodically interlaced to form parallel hollow sections. The hollow sections are shape set to form cylindrical hollows as seen in Fig. 9 showing the final geometry of the 3D NiTi textile.

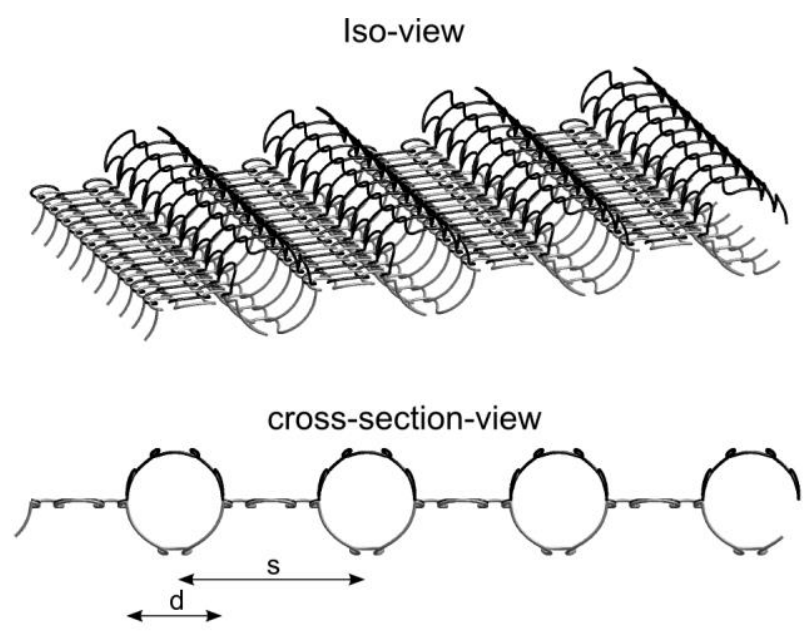

Figure 9. Model of 3D NiTi textile featuring hollow crosssection that reversibly deforms in response to applied external loads and changing temperature. The cross-section is characterized by diameter $d$ of cylindrical hollows and their spacing $s$.

To prove the concept of the temperature responsive 3D textile, a sample was manufactured from a cold drawn 0.1 $\mathrm{mm}$ NiTi wire with nominal composition of 50.3 at. $\%$ Ni. After the shape setting, the wire shows reverse transition temperature to Austenite at about $60^{\circ} \mathrm{C}$ while below $50^{\circ} \mathrm{C}$ the wire presents the R-phase (Fig. 10b); the martensite finish temperature is about $-60^{\circ} \mathrm{C}$. As for geometrical parameters, the sample was $70 \mathrm{~cm}$ long, $40 \mathrm{~cm}$ wide and the cross-section was formed by cylindrical hollows of 
diameter $8.5 \mathrm{~mm}$ spaced about $9 \mathrm{~mm}$ apart. Note that the sample was as light as 2 grams.

Fig. 10a shows the response of the sample to one heatingcooling cycle while subjected to two dead loads of $1 \mathrm{~kg}$ and $2 \mathrm{~kg}$ (2000 times the sample weight). Clearly, the sample changes reversibly the height of the cross-section by more than $2 \mathrm{~mm}$ i.e. $\sim 25 \%$ of the initial height. The temperatures at which the height changes fall within the range of austenite-R-phase transformation (Fig. 10b). The simplified cross-section deformation undergone during the change of the cross-section height is schematically shown in in-set boxes in Fig. 10a.

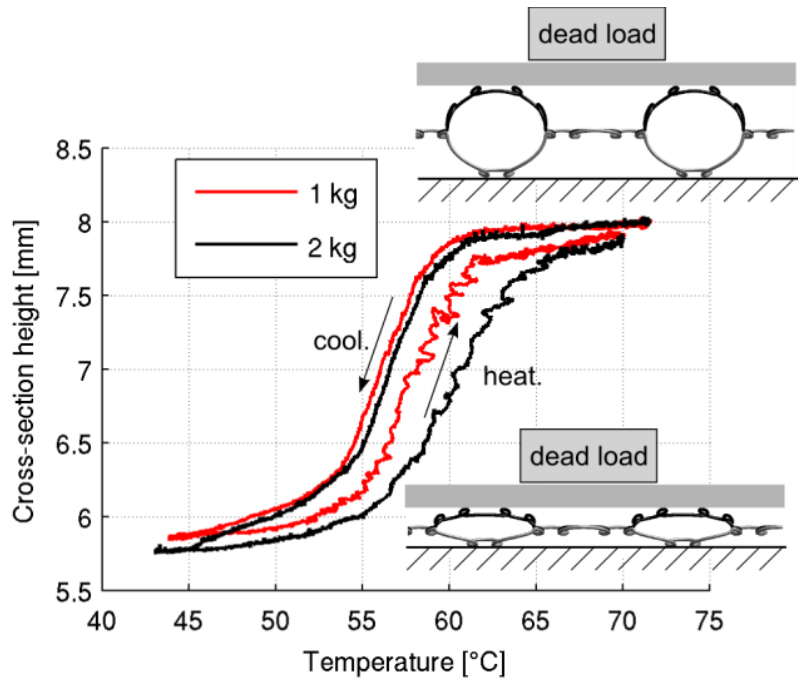

a)

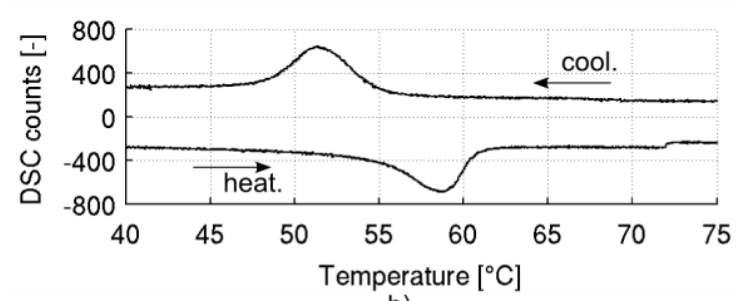

b)

Figure 10. a) The functional response of proof-of-concept 3D NiTi textile in terms of reversible cross-section height change induced by dead load and changing temperature ; in-set pictures show the textile cross-section and its deformation causing the change of the textile height. b) DSC curve measured on the NiTi wire out of which the 3D NiTi textile was made; DSC peaks related to reversible Austenite-R-phase transformation coincide well with cross-section height response to changing temperature shown in a).

\section{Conclusions}

Critical issues related to textile processing of thin $\mathrm{NiTi}$ wires were discussed

- Shape setting of constrained textiles relieves elastic deformation energy from NiTi wires resulting in setting the shape of entire textile as well as fixing the textile patterns. Critical issue is the high shape setting temperatures to which common textile fibres don't resist. - Excessive material waste for weaving and warp knitting textile processing technologies.
- Low friction of NiTi wires making some textile patterns such as woven ones unstable prone to becoming irregular.

Taking into account the issues listed above, we identified weft knitting as the most suitable technology for prototyping as it combines the following advantages:

-Fast textile processing with negligible material waste. -Highly stretchable textile that can take advantage from shape setting.

-Shape setting can be effectively used to tune the mechanical response.

- Mechanical response dominated by deflections of knits.

We demonstrated proof-of-concept of weft knitted NiTi textiles that take advantage from temperature induced change of Young's modulus of NiTi wires combined with deflection dominated local deformation of weft knitted patterns, and smart weft knitted patterns. This approach allowed to design NiTi textile based "high strokes-low forces" actuator and temperature responsive $3 \mathrm{D} \mathrm{NiTi}$ textiles with adaptive cross-section.

\section{References}

1. L. Heller, A. Kujawa, P. Šittner, M. Landa, P. Sedlák, J. Pilch, Eur. Phys. J.-Spec. Top. 1587 - 14 (2008)

2. R. Delville, B. Malard, J. Pilch, P. Sittner, D. Schryvers, Int. J. Plast 27, 282-297 (2011)

3. P. Sedmák, P. Šittner, , J. Pilch, C. Curfs, Acta Mater. 94, 257 - 270 (2015).

4. L. Heller, D. Vokoun, P. Sittner, H. Finckh, Smart Mater. Struct. 21, (2012).

5. http://www.avalon-eu.org, accessed on June 30, 2015

6. P. Šittner, V. Novák, M. Landa, P. Lukáš, Mat. Sci. Eng. A-Struct. 22, 12 - 22 (2007)

7. P. Šittner, V. Novák, L. Heller, P. Sedlák, M. Landa and J. Van Humbeeck, Proceedings of the Materials \& Processes for Medical Devices Conference, 7-11 May 2006, Asilomar, California, USA, Eds B.Berg, M.R.Mitchel, J. Proft, 553-568 (2008).

8. A. R. Pelton, S. M. Russell, J. Di Cello, JOM 55, 33 -37 (2003).

9. J. Abel, J. Luntz, D. Brei, Smart Mater. Struct. 22, (2013). 